\title{
Catheter-based ablation of supraventricular tachycardias in a paediatric population - a decade of experience at a single centre
}

\author{
David Backhoff*, Sophia Bahrke, Thomas Kriebel, Matthias Müller, Heike Schneider, Thomas Paul, Ulrich Krause
}

From 50th Workshop for Pediatric Research

Göttingen, Germany. 20-21 March 2014

Accessory atrioventricular pathways (AP) and dual AV nodal physiology are common substrates for paroxysmal supraventricular tachycardias (SVT) in children and adolescents. Definitive treatment can be achieved by catheter ablation with either radiofrequency (RF) or cryoenergy. Aim of this study was to assess effectiveness and safety of RF- and cryoenergy ablation in a paediatric population.

During the last 10 years $562 \mathrm{EP}$ studies have been performed in 479 children and adolescents at our institution. Median age was 12.1 yrs (range $0.4-19.8$ ). Indications included patient's preference $(67.3 \%)$, drug refractory SVT (31.5\%) and malignant arrhythmias (1.2\%). RF was used in $75 \%$, cryoenergy in $16 \%$, both energy sources in $8 \%$. No ablation was performed in $1 \%$. Congenital heart disease was present in 39 children (6.9\%).

Substrates documented were APs in $54.6 \%$ and AVNRT in $42.6 \%$. APs and AVNRT combined were present in $2.8 \%$. APs were interrupted in $90.5 \%$ (RF) / 90\% (cryoenergy). Dual AV nodal physiology was successfully treated in $98.5 \%$ (RF) / 100\% (cryoenergy). In 70 patients, repeated EPS due to SVT relapse or recurrent preexitation pattern was necessary. In 3 patients (0.5\%) pacemaker implantation due to AV-block after RF ablation was necessary (AVNRT $\mathrm{n}=2 ; \mathrm{AP} \mathrm{n}=1$ ). Routinely performed coronary angiography showed insignificant coronary artery narrowing in 2 patients $(0.3 \%)$ after RF ablation of right posteroseptal AP. In 1 case $(0.2 \%)$, thrombosis of the right coronary artery occurred after intercoronary mapping with a $2 \mathrm{~F}$ catheter. In 2 cases $(0.3 \%)$, pericardial effusion was evident and required puncture after cryo- and RF- ablation, respectively. Vessel injuries at the puncture site with need for surgical intervention occurred in 6 cases (1\%).

Department of Paediatric Cardiology and Intensive Care Medicine, University Medical Center Göttingen, Göttingen, Germany
Catheter ablation of SVT in children and adolescents was safe and effective. Major complications were noted after RF-application only. Therefore, cryoenergy may be considered as energy source of choice for ablation in the rightseptal area.

Published: 11 September 2014

doi:10.1186/2194-7791-1-S1-A29

Cite this article as: Backhoff et al:: Catheter-based ablation of supraventricular tachycardias in a paediatric population - a decade of experience at a single centre. Molecular and Cellular Pediatrics 2014 1(Suppl 1):A29.

\section{SpringerOpen ${ }^{\odot}$}

C 2014 Backhoff et al; licensee Springer This is an Open Access article distributed under the terms of the Creative Commons Attribution License (http://creativecommons.org/licenses/by/2.0), which permits unrestricted use, distribution, and reproduction in any medium, provided the original work is properly cited.
Submit your manuscript to a SpringerOpen ${ }^{\circ}$ journal and benefit from:

- Convenient online submission

- Rigorous peer review

- Immediate publication on acceptance

- Open access: articles freely available online

- High visibility within the field

- Retaining the copyright to your article

Submit your next manuscript at $>$ springeropen.com 